\title{
Algumas CONSIDERAÇÕES SOBRE O USO DA EMPATIA EM CASOS E SITUAÇŌES LIMITE
}

\author{
Perla Klautau de Araujo Pimentel* \\ Nelson Coelho Junior**
}

Resumo

Este artigo visa contribuir para a construção, por meio do conceito axial de empatia, de uma abordagem teórica e prática que oriente o manejo clínico de casos e situaçóes limite, refratários ao método psicanalítico clássico. $\mathrm{O}$ exame da noção de empatia será realizado a partir de três perspectivas: como modalidade de escuta, como forma de comunicação e como fator terapêutico. Nossa proposta é a de dar sustentação à adoção da empatia como ferramenta clínica capaz de ampliar o horizonte de intervenção, incluindo possibilidades de ação que o método interpretativo não comporta.

Palavras-chave: empatia; interpretação; casos-limites.

\section{Abstract}

\section{SOME NOTES ABOUT THE USE OF EMPATHY IN BORDERLINE CASES AND SITUATIONS}

The article aims to contribute to the construction, through the axial concept of empathy, of both a theoretical and clinical approach which may offer some guidance on the management of borderline cases and situations not easily treated by the classical psychoanalytical method. The study of the notion of empathy will be done from three perspectives: as a mode of listening, as a form of communication and as a therapeutic factor. Our goal is to sustain the adoption of empathy as a clinical tool that allows the expansion of the limits of intervention, including new possibilities of action not provided by the interpretative method alone.

Keywords: empathy; interpretation; borderline cases.

* Psicanalista; Mestre e doutora em Psicologia Clínica pela Pontifícia Universidade Católica do Rio de Janeiro (PUC-Rio); Pós-doutoranda do Instituto de Psicologia da Universidade de São Paulo (USP).

** Psicanalista; Doutor em Psicologia Clínica e professor do Instituto de Psicologia da Universidade de São Paulo (USP). 


\section{INTRODUÇÃO}

A problemática discutida no presente trabalho tem início nos anos 1920, mais especificamente quando Freud e seus discípulos se depararam com limites que os fizeram questionar a eficácia da técnica interpretativa. O tratamento clássico das neuroses consistia em uma talking cure, sustentada pela associação livre por parte do analisando, pela atenção flutuante e pela interpretação do material edípico recalcado por parte do analista. Diante dos desafios proporcionados pelos quadros psicopatológicos que não se amoldam ao tratamento padrão dos conflitos edipianos, o estudo de conceitos e operadores clínicos capazes de fazer face às limitações impostas pelo método interpretativo torna-se imprescindível para o alargamento do horizonte psicanalítico. O uso da empatia deve ser entendido como um fator decisivo no manejo de casos e situações clínicas nas quais o tratamento esbarra em obstáculos que limitam o poder das intervenções verbais do analista. São quadros que conduzem a clínica psicanalítica aos limites do interpretável e que não se alinham à classificação organizada em torno das definições tradicionais de neurose, psicose e perversão. Tais casos, situados na fronteira entre essas três estruturas, recebem o mais variado tipo de nomenclatura, englobando uma ampla gama de experiências que têm em comum a dificuldade de simbolização.

Para analisar os diferentes quadros psicopatológicos refratários às abordagens clínicas tradicionais, é necessário um remanejamento da técnica apoiado em uma melhor compreensão dos modos de subjetivação que encontram raízes nas experiências vividas nas fases mais precoces da constituição do psiquismo. Isto implica elucidar o processo intersubjetivo que se passa nos primórdios da vida psíquica, quando o bebê, ainda sem o equipamento linguístico que adquirirá posteriormente, organiza o seu mundo vivido por meio de um complexo processo de agenciamento de sentidos, disposiçôes, padrōes de resposta ao meio, etc, que já começa a moldar decisivamente sua singularidade no mundo. As experiências vividas nessa fase inicial da vida imprimem marcas decisivas no processo por meio do qual o bebê se subjetiva, moldando assim suas inclinações, suas preferências, suas formas de gozar e sofrer, sua forma de agir no mundo, seu modo de sentir e responder às injunçōes da vida.

Do ponto de vista clínico é importante notar que a maior parte das marcas impressas nesta fase inicial da vida psíquica permanece gravada num plano de difícil acesso por meio da palavra, da memória verbal e, consequentemente, da interpretação. Formam parte de um imenso território psíquico inscrito na memória corporal, governado por mecanismos inconscientes dificilmente acessíveis por meio de intervenções verbais, pois sua inscrição é anterior à emergência do sujeito 
linguisticamente organizado. Trata-se de uma memória e de uma forma de conhecimento de si e do mundo de natureza procedural, ou seja, não mediadas pelos conceitos e significados que a linguagem tornará possível mais adiante na vida. Ela está inscrita mas não escrita, por assim dizer, na memória, no funcionamento psíquico do sujeito. Para que se tenha acesso a esse plano da experiência subjetiva é preciso contar com modos de conhecimento e de interação com o outro que não dependam da operação verbal, que permitam uma aproximação e entendimento do sentido da experiência do outro com base na percepção, na ressonância afetiva e na sintonia emocional.

É neste sentido que a empatia ganha uma importância decisiva como operador clínico, abrindo caminhos alternativos para o método interpretativo. A empatia é um fenômeno que se dá no campo da experiência pré-reflexiva. Ela indica a capacidade de estabelecer um contato direto, ou seja, não mediado por palavras ou conceitos, com estados afetivos de outro ser humano. Ela implica, portanto, um modo de cognição perceptual, que se dá fora do campo verbal, discursivo ou proposicional. Desta forma, pode ser caracterizada como uma forma de escuta. Além disso, ela se constitui também como um modo de comunicação entre sujeitos, que acontece independentemente da intenção consciente, permitindo que se estabeleça um tipo de troca subjetiva sem a intervenção da fala. Como consequência do impacto desta troca, modificaçôes na experiência dos sujeitos podem ocorrer. Deste modo, a empatia pode operar na clínica como um fator de transformação. Em outras palavras, ela age como um fator terapêutico. A empatia, portanto, se apresenta como um conceito e uma experiência capazes de oferecer importantes subsídios para a análise de casos e situaçôes limite.

\section{CASOS E SITUAÇÕES LIMITE: OBSTÁCULOS IMPOSTOS À TÉCNICA INTERPRETATIVA}

A discussão sobre os limites impostos à técnica interpretativa não é nova. Pelo contrário, como já foi dito, a problemática em questão está presente no cenário psicanalítico desde 1920. Em nota para o artigo freudiano de 1937 (1990) intitulado "Análise terminável e interminável", Strachey se refere ao pessimismo de Freud em relação ao alcance da eficácia terapêutica da psicanálise. Certamente, o pessimismo de Freud reflete seu encontro com casos não analisáveis pelo método clássico. A expressão casos e situaçôes-limite é uma das formas de designar determinados momentos de uma análise em que a técnica interpretativa encontra um limite no que diz respeito ao seu funcionamento. 
Quatro anos antes de escrever "Análise terminável e interminável” (Freud, [1937] 1990), mais especificamente, na "Conferência XXXIV", Freud ([1933] 1990) declara que nunca fora um terapeuta entusiasta e mostra-se ciente dos sucessos e dos obstáculos inerentes ao processo analítico. No que se refere à eficácia da técnica analítica, afirma que esta se encontra diretamente ligada ao montante de rigidez psíquica presente e à forma da doença tratada. Freud afirma que "por maiores que sejam a elasticidade da vida mental e a possibilidade de reviver antigas situações, nem tudo pode ser trazido à luz novamente" (Freud, [1933] 1990: 152), já que certas modificações na vida psíquica parecem ter se tornado definitivas, permanecendo sob a forma de processos mentais enrijecidos.

A rigidez psíquica caracterizada pelas modificaçōes que se cristalizam sob a forma de cicatriz, em "Análise terminável e interminável” (Freud, [1937] 1990), recebe o nome de alteraçôes do ego. Este termo deve ser entendido como uma cicatriz adquirida nos primeiros anos do desenvolvimento infantil. As alterações efetuadas no ego são resultado do uso dos mecanismos de defesa desenvolvidos a fim de evitar as primeiras situações de perigo, angústia e desprazer. Na maioria das vezes, o analisando repete essas reações durante o trabalho analítico. Tal fato impõe obstáculos aos esforços efetuados por parte do analista, já que os mecanismos de defesa tornam-se modalidades regulares de reação do caráter, encontrando-se distanciados do conflito inconsciente. Desta forma, para atingir as alteraçôes do ego, é preciso que se empreenda uma análise dos mecanismos de defesa. É neste momento que os obstáculos se colocam no caminho da cura: "a dificuldade em questão é que os mecanismos defensivos dirigidos contra um perigo anterior reaparecem no tratamento como resistências contra o próprio restabelecimento" (Freud, [1937] 1990: 271). Sendo assim, durante o trabalho com as resistências, o eu deixa de cumprir o acordo em que a situação analítica se funda, desobedecendo à regra fundamental. $\mathrm{O}$ corolário disso é que o eu se retrai e a confiança no analista é abalada. $\mathrm{O}$ analisando passa a tratar o analista como um estranho "que lhe está fazendo exigências desagradáveis, e comporta-se com ele exatamente como uma criança que não gosta do estranho e que não acredita em nada do que este lhe diz" (Freud, [1937] 1990: 272). Diante de tal comportamento, Freud encontra duas saídas: considerar o caso não analisável ou prolongar a duração do tratamento.

Preocupado com a legitimação científica da psicanálise, Freud transfere a incumbência de prolongar a duração do tratamento e de encontrar técnicas capazes de atestar o sucesso do método analítico para seus mais notáveis discípulos. Nessa tarefa, quem mais se destacou foi Ferenczi. Apesar de não se incumbir diretamente dos casos que exigiam uma análise de longa duração, Freud manteve-se atento ao trabalho efetuado pelos seus seguidores. Em se tratando da aná- 
lise das resistências, no $V$ Congresso Psicanalítico Internacional realizado em $\mathrm{Bu}$ dapeste, Freud recomenda uma mudança de atitude do analista: nos casos em que a análise da transferência não se apresenta como recurso suficiente para vencer as resistências e desentravar o processo, cabe ao analista adotar uma postura mais ativa. Uma maior atividade do analista era necessária devido ao fato de a interpretação não fazer estremecer os obstáculos erigidos durante a análise dos mecanismos de defesa: "não parece natural que o devamos ajudar de outra maneira, colocando-o na situação mental mais favorável à solução dos conflitos que temos em vista?" (Freud, [1918] 1990: 204). "Acho", declara Freud, "que uma atividade dessa natureza, por parte do médico que analisa, é irrepreensível e inteiramente justificada" (idem). Para Freud, este tipo de ação deve ser efetuado sob privação - num estado de abstinência. Seguindo esta recomendação, no ano seguinte, Ferenczi estabelece a técnica ativa como medida a ser utilizada com pacientes resistentes ao método interpretativo.

Em 1920, na sua comunicação apresentada no VI Congresso da Associação Internacional de Psicanálise, intitulada "Prolongamentos da 'técnica ativa' em psicanálise”, Ferenczi ([1920] 1993) apresenta as primeiras formulações a respeito dos procedimentos técnicos utilizados com os pacientes resistentes ao método interpretativo. Ao seguir o princípio de abstinência recomendado por Freud, Ferenczi aposta na frustração, ou melhor, no aumento da tensão - suscitado através do desprazer imposto pela realização de uma tarefa obrigatória ou pela renúncia a certas ações agradáveis (excitação masturbatória das partes genitais, estereotipias e tiques, ou excitações de outras partes do corpo) - como meio de exacerbar os sintomas e aumentar a violência do conflito. De acordo com essa lógica, a atividade provoca o aumento de tensão e, consequentemente, o recrudescimento da resistência, ao irritar a sensibilidade do ego (Ferenczi, [1920] 1993). O resultado disso é a perturbação da "tranquilidade de regiōes psíquicas distantes ou profundamente recalcadas que a análise tinha até então poupado, de sorte que seus produtos encontram - sob a forma de ideias significativas - o caminho da consciência" (ibid.: 124). De forma resumida, é através do aumento de tensão que o material recalcado torna-se consciente e pronto para ser analisado.

Seis anos depois, em seu artigo "Contraindicações da técnica ativa", Ferenczi ([1926] 1993) nota que tal artifício, ao invés de diminuir, aumenta a resistência ao tratamento: "a atividade, na medida em que se propõe a aumentar a tensão psíquica - mediante recusas, injunções e interdições desagradáveis - a fim de obter um material novo, vai exacerbar inevitavelmente a resistência do paciente" (ibid.: 366). Desta forma, o aumento da tensão que era tido como ponto- 
chave para a análise das resistências passa a ser adotado como uma contraindicação para o avanço do processo analítico que se encontra emperrado. Diante de tal constatação, o aumento da tensão provocado pela frustração imposta por um comportamento ativo do analista deveria ser abrandado: "as nossas instruções ativas não devem ser, segundo a expressão de um colega que analisei, de uma intransigência estrita, mas de uma flexibilidade elástica" (ibid.: 367-368). Seguindo esta pista, dois anos mais tarde, Ferenczi propõe uma elasticidade da técnica psicanalítica que será adotada como nova ferramenta terapêutica.

Em 1928, na conferência intitulada "Elasticidade da técnica psicanalítica", Ferenczi ([1928] 1993), postula a noção de tato psicológico como norteadora da ação do analista. Tato psicológico é definido como "a faculdade de 'sentir com' (Einfulung)", como o estabelecimento de um contato empático que tem a função de possibilitar uma compreensão emocional de "quando e como se comunica alguma coisa ao analisando" (ibid.: 27). Ao usar o tato como guia durante as sessões, Ferenczi introduz um novo ingrediente à técnica analítica: a empatia (Chertok e Stengers, 1990).

A introdução da empatia na cena psicanalítica coloca em ato o afastamento de Ferenczi em relação ao método ativo recomendado e aprovado por Freud. Deve ficar claro que a atividade introduzida na técnica clássica não era concebida como uma inovação, mas sim como uma adaptação que não transgredia a regra da neutralidade. Afinal, a técnica ativa equivalia a um instrumento, a uma espécie de artifício com uso restrito e temporário cujo intuito era o de provocar ou acelerar a investigação do material psíquico inconsciente. Depois de atingir este objetivo, cabia ao analista retornar à posição de neutralidade. Como é sabido, um dos motivos que impulsionaram Freud a criar a regra da neutralidade foi o de afastar a psicanálise da sugestão e singularizá-la como ciência. Neste ponto, é importante notar que o uso da empatia representava uma ameaça de retorno a vivências guiadas pelo afeto que a regra da neutralidade e o estabelecimento do enquadre analítico tiveram a função de dissipar.

\section{EMPATIA: NOVO INGREDIENTE OU RETORNO ÀS ORIGENS?}

Se, por um lado, o uso da empatia poderia ser encarado como uma ameaça de retorno aos tempos pré-psicanalíticos, por outro, a introdução da empatia representava um novo ingrediente à cena analítica. Ferenczi foi o primeiro analista a utilizar a empatia como ferramenta clínica ${ }^{1}$. A noção de tato psicológico foi con- 
cebida como um instrumento capaz de superar gradualmente os limites impostos pelo método interpretativo. Neste sentido, o tato tem a função de fornecer uma compreensão empática dotada da capacidade de colocar o analista no mesmo diapasão do analisando. Dessa forma, o analista passa a participar da sessão com seus processos psíquicos, tornando-se parte do processo de simbolização com sua presença sensível. Isto provoca uma mudança referente à qualidade da presença do analista que inclui todo o seu funcionamento mental, envolvendo mudanças de sensibilidade e percepção. Com isto, o analista desloca sua presença do recuo estratégico que lhe permite estar atento ao discurso do paciente de modo flutuante e torna-se parte integrante da tarefa de acessar o material recalcado.

Durante as duas décadas posteriores, a empatia não se consolidou como ferramenta clínica. Num movimento análogo ao efetuado por Ferenczi em relação à técnica ativa, Kohut, no final dos anos cinquenta, concede à empatia um lugar de destaque. Ao se posicionar contra a análise das defesas, valorizada como o aspecto central da cura pela psicologia do ego, Kohut faz da empatia a palavrachave de seu vocabulário, concebendo-a como o instrumento principal da psicanálise. No artigo de 1959, "Introspection, empathy, and psychoanalysis - An examination of the relationship between mode of observation and theory", a empatia é conceituada como um método de observação e coleta de dados que delimita o campo psicanalítico.

Sem fazer referências a Ferenczi, Kohut adota uma visada científica e define a empatia como o constituinte essencial da observação de fenômenos psicológicos. Partindo da constatação de que não é possível utilizar os órgãos do sentido para examinar o mundo interno, Kohut postula que para entrar em contato com conteúdos psíquicos é imprescindível fazer uso da empatia. Diferentemente do que ocorre com o observador de fenômenos físicos, cabe ao psicanalista - observador de fenômenos psíquicos - empatizar com o outro e, a partir daí, coletar dados. Do primeiro para o segundo, há uma mudança de posição: o observador deixa de adotar uma postura de distanciamento do fenômeno observado e passa a participar ativamente, tornando-se parte da observação. Ao postular a empatia como método de observação, Kohut procura dar à psicanálise caráter científico. Para tal, não poupa esforços na direção de legitimar a empatia como modalidade de escuta terapêutica.

No artigo de 1959, Kohut refere-se a Breuer e a Freud como pioneiros no emprego científico da empatia e afirma que a associação livre e a análise das resistências são instrumentos auxiliares, empregados a serviço do método introspectivo e empático. Neste sentido, a empatia é definida como pilar da psicanálise. Para fazer valer seu ideal científico, Kohut tem a preocupação de deixar claro que, ao 
fazer uso da empatia, o analista não perde a objetividade da observação. Pelo contrário, ao lado desta, uma dimensão subjetiva é instalada. Portanto, quando o analista assume a postura de observador participante, os campos objetivo e subjetivo passam a coexistir ${ }^{2}$.

Além de conferir status científico à psicanálise, Kohut faz da empatia uma ferramenta clínica. Concebida não só como modalidade de escuta, a empatia também é conceituada como um processo de comunicação que, por si só, possui efeito terapêutico. De acordo com o vocabulário kohutiano, a empatia é definida como sinônimo de introspecção vicariante, ou seja, como uma introspecção no lugar do outro. A ideia é que, ao entrar em sintonia com os conteúdos não verbais, o analista identifica-se com os afetos de seu analisando, obtendo, assim, uma compreensão emocional destes. Seguindo este raciocínio, a empatia pode ser definida como uma forma particular de percepção que é utilizada como ferramenta clínica, isto é, como via de acesso ao material inconsciente recalcado.

\section{EMPATIA: UMA FERRAMENTA CLÍNICA PARA A ANÁLISE DE CASOS E SITUA- ÇÓES-LIMITE}

As inovações propostas por Ferenczi e Kohut geraram frutos. As ideias do primeiro foram acolhidas e desenvolvidas na Inglaterra pelos psicanalistas do chamado Middle Group, em especial por Winnicott e Balint. O trabalho de Kohut nos Estados Unidos tornou-se a base para o desenvolvimento da psicologia do self. Atualmente, as medidas referentes à elasticidade da técnica analítica propostas por Ferenczi como alternativas à técnica ativa e a reabilitação da empatia efetuada por Kohut como mudança do dispositivo clínico utilizado pela psicologia do ego tornaram-se algumas das principais referências relativas ao enfrentamento dos impasses da clínica psicanalítica.

Seguindo o caminho aberto por estes dois pioneiros, surgem algumas indagações: que uso o analista pode fazer da empatia no manejo de casos e situações limite? Como a empatia pode ser utilizada como ferramenta clínica para superar os entraves impostos pelo método clássico? Como é possível, através da empatia, ter acesso aos conteúdos que foram inscritos no psiquismo mas não sofreram o processo de recalcamento? Para obter elementos que auxiliem a responder tais perguntas, a empatia deve ser examinada a partir de três perspectivas: como modalidade de escuta, como forma de comunicação e como fator terapêutico.

A primeira perspectiva foi desenvolvida por Ferenczi e Kohut por meio, respectivamente, das noções de tato psicológico e de introspeç̧ão vicária. Em ambas, 
a empatia é considerada condição prévia para a interpretação. Quando Ferenczi ([1928] 1993) propõe o tato psicológico como modalidade de escuta, ele o faz com base numa premissa: o tato - ou seja, a faculdade de sentir com - funciona como uma bússola para a ação do analista. Ao usar este tipo de compreensão emocional como guia durante as sessões, o analista percebe "quando se deve calar e aguardar outras associações; e em que momento o silêncio é uma tortura inútil para o paciente, etc" (Ferenczi, [1928] 1993: 27). Desta forma, o uso da empatia informa o momento oportuno para a interpretação do conteúdo pulsional recalcado.

No manejo de casos e situações limite, a interpretação passa a não funcionar como uma ferramenta clínica eficaz e, consequentemente, o processo analítico esbarra em obstáculos que limitam o poder das intervenções verbais do analista. Isto ocorre porque o material inconsciente em jogo foi inscrito no psiquismo em uma época do desenvolvimento infantil anterior ao estabelecimento do status de unidade do eu. Nestes casos, a técnica interpretativa clássica deve ser deixada de lado. O que está em jogo não é a decifração do conteúdo inconsciente recalcado, mas sim a integração de experiências que, embora não discursivamente organizadas, são articuladas, ordenadas e carregadas de sentido ${ }^{3}$.

Este é o momento oportuno para fazer uso da empatia como forma de comunicação. Tal faceta da empatia encontra seu fundamento no modo mais primitivo de comunicação, a relação mãe-bebê. Ferenczi e Kohut, pioneiros no uso psicanalítico da empatia, reconheceram a importância da investigação desta temática mas não se dedicaram a ela. Herdeiro da tradição ferencziana, e pediatra de formação, Winnicott foi um dos psicanalistas que mais se dedicaram ao exame do estabelecimento das primeiras relações do bebê com seu entorno. Algumas de suas principais elaborações teóricas refletem a importância dada à relação mãe-bebê como primeira forma de comunicação.

Em sua teorização sobre o desenvolvimento emocional primitivo, Winnicott parte do que ele concebe como paradigma das primeiras formas de comunicação estabelecidas entre o recém-nascido e sua mãe: a amamentação. Esta relação inicia-se numa época em que o psiquismo não se encontra plenamente estruturado. Desta forma, o papel desempenhado pelos cuidados maternos possui a função de promover a maturação do psiquismo, contribuindo de maneira crucial para a facilitação ou para o comprometimento do desenvolvimento infantil. De acordo com o vocabulário winnicottiano, cuidados maternos e ambiente devem ser considerados sinônimos, já que, no início, a mãe funciona, tanto em termos biológicos quanto em termos psicológicos, como o primeiro ambiente para o bebê. Com a criança ainda no útero, ou no colo sendo segurada e cuidada, a mãe fornece o 
ambiente físico que gradualmente torna-se psicológico. O importante nesta equivalência de termos é perceber que a mãe, em um primeiro momento, é mãeambiente. E mais: ambiente, mãe e cuidados maternos não podem ser pensados de forma separada do bebê.

Winnicott ([1945] 2000) postula um estado inicial de indiferenciação eunão-eu, cuja unidade não é o indivíduo isolado mas sim o conjunto ambienteindivíduo. Isto quer dizer que, no começo da vida, o bebê forma com os cuidados maternos uma unidade. Unidade esta que é dual, isto é, constituída por um recém-nascido absolutamente dependente dos cuidados maternos e por uma mãe que se encontra em um estado de preocupação materna primária. Winnicott ([1956] 2000) descreve esta noção como um estado psicológico em que toda mulher grávida sadia ingressa pouco antes de dar à luz. Quando a mãe é acometida pela preocupação materna primária, ela é capaz de empatizar com seu bebê. Um estado aguçado de sensibilidade é aflorado, fazendo com que ela atenda às necessidades de seu filho, estabelecendo assim um tipo refinado de sintonia: "em grande parte ela é o bebê e o bebê é ela" (Winnicott, [1966] 1999: 4). O bebê, por sua vez, é completamente dependente dos cuidados maternos, a ponto de não se diferenciar deles. Nesta época, os cuidados maternos ainda não são percebidos como tais, e sequer se são bem ou mal desempenhados. Em tal momento, é indiferente saber se existe ou não alteridade, pois para o bebê ainda não há a percepção da exterioridade.

Para entender o que foi descrito acima, é necessário examinar o funcionamento da mãe e do bebê, observado por Winnicott ([1945] 2000) naquilo que ele denomina como a experiência da primeira mamada teórica. Enquanto a mãe atesta sua presença fornecendo o seio e o seu desejo de alimentar um bebê faminto, o bebê é capaz de conceber a ideia de que algo irá satisfazer sua necessidade: encontramos aqui uma área de superposição denominada momento de ilusão. "Em outras palavras, o bebê vem ao seio, quando faminto, pronto para alucinar alguma coisa que pode ser atacada. Nesse momento aparece o bico real, e ele pode sentir que esse bico era exatamente o que ele estava alucinando" (Winnicott, [1945] 2000: 227). A superposição dos dois processos revela uma área intermediária de experiência que abarca uma situação de "mutualidade" (Winnicott, [1969] 1994: 198). Este tipo de experiência deve ser entendido como um processo silencioso que marca o início da comunicação humana: por meio da capacidade de empatizar com as necessidades do bebê, a mãe oferece a possibilidade de o bebê identificarse com ela. É a partir destes momentos de identificação que o bebê inicia o processo de integração de suas experiências em termos de espaço-tempo, constituindo, assim, os primeiros rudimentos de um sentimento de self. 
O que se observa no manejo de casos e situaçôes limite são dificuldades ou situações traumáticas ocorridas nesses estágios precoces do desenvolvimento, o que traz como consequência uma não realização ou uma perturbação do processo de integração pessoal. Esta perturbação não se expressa através do recalcamento de desejos. Ela se expressa no modo como a relação com o ambiente é organizada: em pacientes cujo status de unidade não se encontra estabelecido, o que está em questão é a situação de dependência absoluta ambiental (Winnicott, [1960] 1990). Mais precisamente, trata-se da dependência dos cuidados inicialmente recebidos de um ambiente confiável.

Nos casos em que a não-integração assume o aspecto dominante da personalidade, é necessário, para que o processo analítico avance, primeiramente a instauração de um ambiente que inspire confiança. Nestes casos, a situação de dependência encontra-se em primeiro plano e fornece "a indicação do paciente ao analista de como ele deve se comportar mais que de como ele deve interpretar" (Winnicott, [1959-1964] 1990: 117). Sendo assim, a técnica adequada consiste no oferecimento de um ambiente de holding capaz de fornecer o suporte necessário para a integração de experiências vividas em momentos anteriores à emergência do sujeito linguisticamente organizado. Na tradução da obra de Winnicott para o português, o termo holding foi mantido com a grafia original. Não foi encontrada nenhuma palavra ou expressão em português capaz de abranger o significado deste termo. Na língua inglesa, a palavra holding é utilizada no sentido do verbo to hold, que possui alguns significados compatíveis com a ideia de Winnicott: segurar, aguentar, sustentar e conter. Sendo assim, a expressão em questão deve ser entendida como uma sustentação proveniente do ambiente que possui a peculiaridade de adaptar-se às necessidades que vão se modificando ao longo do tempo. É esta espécie de manejo não-interpretativo que possibilita ao sujeito ainda não integrado restabelecer o status de unidade. Portanto, nestes casos, a provisão ambiental encontra-se em primeiro plano: o que está em questão é a constância, a sustentação e a adaptação empática do analista às necessidades do paciente ainda não integrado (Winnicott, [1969] 1994).

De acordo com esta lógica, ambiente, setting terapêutico e a pessoa do analista devem ser considerados equivalentes. O setting deve ser encarado como parte integrante da personalidade do analista - tornando-se, assim, peça fundamental para a construção do sentimento de confiança (Salem, 2006). Neste contexto, a empatia atua como um fator terapêutico, operando como elemento crucial para o estabelecimento de uma relação de confiabilidade entre o analista e o analisando. Deste modo, o setting deve ser encarado como parte integrante 
da personalidade do analista (Winnicott, [1954a] 2000, [1954b] 2000). Isto inclui a totalidade de elementos que constituem o relacionamento analítico dos quais a contratransferência merece destaque. Numa visão ampliada, a contratransferência não se encontra limitada aos aspectos positivos ou negativos produzidos pela transferência, ela vai além: abrange todo o funcionamento mental do analista (Green, [1975] 1986).

A condução da análise de casos e situações limite exige que o analista se afaste de uma posição baseada prioritariamente na escuta do material inconsciente recalcado e adote uma posição mais ativa, participando com sua presença sensível do processo analítico. A adoção de uma certa atividade provoca uma mudança na qualidade da presença do analista, que passa a incluir todo o seu funcionamento mental, envolvendo mudanças de sensibilidade, de atenção e de percepção. Ao estabelecer um contato empático, o analista se coloca no mesmo diapasão do paciente e passa a participar da sessão com seus processos psíquicos. Isto significa que os processos perceptuais e cognitivos do analista tornam-se parte do processo de integração do sujeito em análise.

Diante de tais consideraçôes, a empatia pode ser considerada uma peça chave para a orientação do manejo clínico de casos e situações refratárias ao método psicanalítico clássico. A adoção da empatia como operador clínico permite um remanejamento da técnica clássica apoiado em uma melhor compreensão dos modos de subjetivação que encontram raízes nas experiências vividas nas fases mais precoces da constituição do psiquismo. Desta forma, o uso da empatia permite ampliar o horizonte de intervenção, incluindo possibilidades de ação que o método interpretativo não comporta.

\section{REFERÊNCIAS BIBLIOGRÁFICAS}

Chertok, L. \& Stengers, I. (1990). O coração e a razão. Rio de Janeiro: Jorge Zahar. Ferenczi, S. (1920). Prolongamentos da "técnica ativa" em psicanálise. In: Sándor Ferenczi:

Obras completas, Psicanálise III (pp. 109-126). São Paulo: Martins Fontes, 1993. - (1926). Contraindicações da técnica ativa. In: Sándor Ferenczi: Obras completas, Psicanálise III (pp. 365-376). São Paulo: Martins Fontes, 1993. . (1928). Elasticidade da técnica psicanalítica. In: Sándor Ferenczi: Obras completas, Psicanálise IV (pp. 25-36). São Paulo: Martins Fontes, 1993.

Freud, S. (1918). Linhas de progresso na terapia analítica. Obras completas, ESB, v. XVII.

Rio de Janeiro: Imago, 1990. 
. (1933). Conferência XXXIV. Obras completas, ESB, v. XXII. Rio de Janeiro: Imago, 1990.

- (1937). Análise terminável e interminável. Obras completas, ESB, v. XXIII. Rio de Janeiro: Imago, 1990.

Green, A. (1975). O analista, a simbolização e a ausência no contexto analítico. In: Sobre a loucura pessoal (pp. 36-65). Rio de Janeiro: Imago, 1986.

Kohut, H. (1959). Introspection, empathy, and psychoanalysis - An examination of the relationship between mode of observation and theory. Journal of American Psychoanalytic Association, 7, 459-483.

. (1981). Introspection, empathy, and the semi-circle of mental health. The International Journal of Psychoanalysis, 63, 395-407.

Pigman, G. W. (1995). Freud and the history of empathy. The International Journal of Psychoanalysis, 76, 237-256.

Salem, P. (2006). A gramática da quietude: um estudo sobre hábito e confiança na formação da identidade. Tese de Doutorado, Instituto de Medicina Social, Universidade do Estado do Rio de Janeiro.

Winnicott, W. (1945). O desenvolvimento emocional primitivo. In: Da pediatria à psicanálise (pp. 269-285). Rio de Janeiro: Imago, 2000.

. (1954a). Aspectos clínicos e metapsicológicos da regressão no contexto psicanalítico. In: Da pediatria à psicanálise (pp. 374-392). Rio de Janeiro: Imago, 2000.

. (1954b). Retraimento e regressão. In: Da pediatria à psicanálise (pp. 347-354).

Rio de Janeiro: Imago, 2000.

. (1956). A preocupação materna primária. In: Da pediatria à psicanálise (pp. 491-498). Rio de Janeiro: Imago, 2000.

. (1959-1964). Classificação: existe uma contribuição à classificação psiquiátrica? In: $O$ ambiente e os processos de maturação: estudos sobre a teoria do desenvolvimento emocional (pp. 114-127). Porto Alegre: Artes Médicas, 1990.

. (1960). Teoria do relacionamento paterno-infantil. In: $O$ ambiente e os processos de maturação: estudos sobre a teoria do desenvolvimento emocional (pp. 38-54). Porto Alegre: Artes Médicas, 1990.

—. (1966). A mãe dedicada comum. In: O bebê e suas mães (pp. 1-11). São Paulo: Martins Fontes, 1999.

- (1969). A experiência mãe-bebê de mutualidade. In: Winnicott, C.; Shepherd, R. e Davis, M. Exploraçôes psicanalíticas (pp. 195-202). Porto Alegre: Artes Médicas, 1994. 


\section{Notas}

1 Embora Freud tenha usado o termo, ele não o fez de forma diretamente relacionada à técnica psicanalítica (Pigman, 1995).

2 Os desdobramentos desta premissa podem ser encontrados em um dos últimos artigos escritos pelo autor (Kohut, 1981).

3 Aqui, sentido diz respeito à ordenação, direcionamento ou regulação do campo experiencial que se dá sem o uso do equipamento semântico da linguagem e que permite a aquisição de um certo tipo de conhecimento (perceptual, não inferencial ou não-discursivo) que possibilita o estabelecimento de padrões de resposta a estímulos e desafios do meio. Nesta acepção, sentido se diferencia de significação, que implica o uso de palavras e que possibilita um tipo de organização semântica da experiência mediada pelo uso de conceitos.

Recebido em 06 de novembro de 2008 Aceito para publicação em 13 de junho de 2009 